\title{
Genetic differentiation among North Atlantic killer whale populations
}

\author{
ANDREW D. FOOTE, $+\dagger$ JULIA T. VILSTRUP, † RENAUD DE STEPHANIS, $\ddagger \S$ PHILIPPE \\ VERBORGH, $\ddagger$ SANDRA C. ABEL NIELSEN,†ROBERT DEAVILLE,- LARS KLEIVANE,** \\ VIDAL MARTÍN, ††PATRICK J. O. MILLER, 柿 NILS ØIEN,§§ MONICA PÉREZ-GIL, †† MORTEN \\ RASMUSSEN, $\dagger$ ROBERT J. REID,-- KELLY M. ROBERTSON,***EMER ROGAN, †† TIU SIMILÄ, 柿 \\ MARIA L. TEJEDOR, †† HEIKE VESTER, §§§--- GÍSLI A. VÍKINGSSON,****ESKE WILLERSLEV, † \\ M. THOMAS P. GILBERT† and STUART B. PIERTNEY* \\ *Institute of Biological and Environmental Sciences, University of Aberdeen, School of Biological Sciences, Tillydrone Avenue, \\ Aberdeen AB24 2TZ, UK, †Centre for GeoGenetics, Natural History Museum of Denmark, University of Copenhagen, Øster \\ Voldgade 5-7, 1350 Copenhagen K, Denmark, 我IRCE, Conservation Information and Research on Cetaceans, C/Cabeza de \\ Manzaneda 3, Algeciras-Pelayo, 11390 Cadiz, Spain, §Departamento de Biologia de la Conservación, Estación Biologica de Doñana, \\ CSIC, C/Americo Vespucio S/N, Isla de la Cartuja, Sevilla 41092, Spain, -Institute of Zoology, Zoological Society of London, \\ Regent's Park, London NW1 4RY, UK, **LKARTS-Norway, 3188 Horten, Norway, ††SECAC, Society for the Study of Cetaceans in \\ Canary Archipelago, Edificio Antiguo Varadero, Local 8B, Puerto Calero, 35571 Yaiza, Lanzarote, Spain, 俦ea Mammal Research \\ Unit, Gatty Marine Laboratory, St Andrews, Fife KY16 8LB, UK, §§Institute of Marine Research, PO Box 1870 Nordnes, \\ 5817 Bergen, Norway, —Wildlife Unit, SAC Veterinary Services, Inverness IV2 4JZ, UK, ***Southwest Fisheries Science Center, \\ 3333 N. Torres Pine Ct, La Jolla, CA 92037, USA, †††Department of Zoology, Ecology and Plant Science, University College, Cork, \\ Ireland, 革列ild Idea, Box 181, 8465 Straumsjøen, Norway, §§§Cognitive Ethology Lab, German Primate Center, Göttingen, \\ Kellnerweg 4, 37077 Göttingen, Germany, _-Max Planck Institute for Dynamics and Self-Organization, Bunsenstr. 10, 37073 \\ Göttingen, Germany, ****Marine Research Institute, Program for Whale Research, PO Box 1390, 121 Reykjavík, Iceland
}

\begin{abstract}
Population genetic structure of North Atlantic killer whale samples was resolved from differences in allele frequencies of 17 microsatellite loci, mtDNA control region haplotype frequencies and for a subset of samples, using complete mitogenome sequences. Three significantly differentiated populations were identified. Differentiation based on microsatellite allele frequencies was greater between the two allopatric populations than between the two pairs of partially sympatric populations. Spatial clustering of individuals within each of these populations overlaps with the distribution of particular prey resources: herring, mackerel and tuna, which each population has been seen predating. Phylogenetic analyses using complete mitogenomes suggested two populations could have resulted from single founding events and subsequent matrilineal expansion. The third population, which was sampled at lower latitudes and lower density, consisted of maternal lineages from three highly divergent clades. Pairwise population differentiation was greater for estimates based on mtDNA control region haplotype frequencies than for estimates based on microsatellite allele frequencies, and there were no mitogenome haplotypes shared among populations. This suggests low or no female migration and that gene flow was primarily male mediated when populations spatially and temporally overlap. These results demonstrate that genetic differentiation can arise through resource specialization in the absence of physical barriers to gene flow.
\end{abstract}

Keywords: behaviour/social evolution, ecological genetics, population ecology, population genetics - empirical, predator-prey interactions

Received 16 December 2009; revision received 27 October 2010; accepted 2 November 2010

Correspondence: Andrew D. Foote, Fax: +45 353213 00;

E-mail: footead@gmail.com 


\section{Introduction}

Understanding the spatial and temporal context of population structure can provide important insights into the underlying intrinsic and extrinsic processes (e.g. Palsbøll et al. 2004; Fontaine et al. 2007, 2010; Pastene et al. 2007). Physical isolation caused by geographic distance or barriers between populations has long been thought to be a principle cause of population structuring (Mayr 1942). For example, populations could become isolated in different nonconnected regions, in glacial refugia or on isolated islands (e.g. Piertney et al. 2005; Jordan \& Snell 2008). The marine environment typically has fewer physical geographic barriers to gene flow than the terrestrial environment (Palumbi 1994), and the energetic cost of movement and therefore dispersal are considered low (Tucker 1975; Williams 1999). However, despite the high dispersal potential, many highly mobile marine species show a high degree of population structuring (e.g. Hoelzel 1998; Pardini et al. 2001; Carlsson et al. 2004), influenced by extrinsic factors such as climatic and oceanographic variation (Fullard et al. 2000; Natoli et al. 2005; Fontaine et al. 2007, 2010) and intrinsic factors such as site fidelity to specific feeding and breeding grounds (FitzSimmons et al. 1997; Palsbøll et al. 1997; Baker et al. 1998).

In the killer whale (Orcinus orca), examination of the spatial and temporal context of population structure has identified both geographic separation and ecological specialization as drivers of population structure (Hoelzel et al. 2007; Morin et al. 2010a). Analysis of mitogenomes shows almost complete lineage sorting of Pacific and Antarctic ecotypes (Morin et al. 2010a), with less gene flow between ecotypes than within them (Hoelzel et al. 2007; Morin et al. 2010a; Pilot et al. 2010). Within the North Atlantic basin, analysis of mtDNA control region sequence variation found lineage sorting between two ecologically and morphologically disparate types (Foote et al. 2009). However, there has been no analysis of biparentally inherited markers to assess sex-biased dispersal and provide greater levels of resolution for specifying genetic structure. Field studies in the Northeast Atlantic have found seasonal specialization on prey resources such as the Norwegian spring-spawning stock of Atlantic herring (Clupea harengus) (Similä \& Ugarte 1993; Similä et al. 1996; Similä 1997a), the Icelandic summerspawning stock of Atlantic herring (Sigurjónsson et al. 1988; Simon et al. 2007), the Northeast Atlantic mackerel (Scomber scombrus) stock (Luque et al. 2006; Foote et al. 2010) and the eastern stock of Atlantic bluefin tuna (Thunnus thynnus) (Guinet et al. 2007; de Stephanis et al. 2008). Direct measure of dispersal by mark-recapture analyses using photo-identification of naturally marked individuals suggests that populations exhibit site fidelity owing to association with these resources and that longrange movement appears to be primarily influenced by the migration of prey (Similä et al. 1996; Esteban-Pavo 2008; de Stephanis et al. 2008; Foote et al. 2010).

Here, we assess patterns of genetic structure among samples of killer whale from across the Northeast Atlantic. We estimate the number of populations that the samples were collected from and assign individuals to different putative populations. We compare mitochondrial DNA haplotype frequency and polymorphic microsatellite allele frequencies of killer whales to investigate whether spatiotemporal isolation results in genetic divergence or whether there is sufficient gene flow to prevent the formation of separate gene pools. We hypothesize that the movement of prey species should influence the spatiotemporal overlap of populations and that population structure will be defined by different prey stocks as previously noted in the mark-recapture data.

\section{Materials and methods}

\section{Sample collection}

Skin samples were obtained from 85 individuals from across the North Atlantic by remote biopsying of freeranging animals (Palsbøll et al. 1991), by necropsy of stranded animals, from wild-born captive specimens (Sigurjónsson \& Leatherwood 1988) and from skin from suction cups of acoustic tags (Johnson et al. 2000). Forty free-ranging animals were sampled from the wintering and summer feeding grounds of the Norwegian springspawning (NSS) stock of Atlantic herring between 2001 and 2007. Based on photo-identification records, a maximum of four individuals from a single pod were thought to be included. One individual was sampled in the North Sea between Shetland and Norway from a pelagic fishing vessel in October 2008 whilst it was feeding on mackerel from the nets. Ten individuals from separate strandings around Scotland, England and the Republic of Ireland between 1994 and 2008 and eight individuals from independent strandings around Iceland were sampled between 1990 and 2008. Samples from a further five captive, but wild-born, Icelandic individuals were included. Ten free-ranging individuals and one stranded individual were sampled from the Strait of Gibraltar between 2006 and 2010. Photoidentification records indicate that these individuals were taken from all five of the pods recorded annually feeding on the Atlantic bluefin tuna in the Strait (see Esteban-Pavo 2008). Nine free-ranging individuals were sampled from two groups, off the South coast of Lanzarote in June 2009, Canary Islands. Killer whales are rarely sighted in this area, and little is known about their ecology. Some individuals had cookiecutter shark 
(Isistius sp.) bite wounds, and some had Xenobalanus barnacles attached to the trailing edge of their dorsal fins as found in killer whales in tropical Pacific waters (e.g. Baird et al. 2005; Pitman et al. 2007; Sakai et al. 2009). The Canary Islands are at the Northern limit of the cookiecutter shark's range, suggesting that these individuals are at least seasonally resident in lower latitude waters. No Isistius wounds or Xenobalanus barnacles were seen on any individuals in more northerly waters including the Strait of Gibraltar. Lastly, two samples were included from the Western North Atlantic, a biopsy sample taken from the Gulf of Mexico during the predation of a sperm whale (Physeter macrocephalus) by a group of killer whales in August 2001, the other taken from a stranded specimen in Newfoundland in 1971. Sample storage varied, with some samples wrapped in aluminium foil and frozen on collection without preservative, whilst others were stored in 20\% dimethyl sulphoxide (DMSO) saturated with $\mathrm{NaCl}$ (Amos \& Hoelzel 1991) or $70 \%$ ethanol (Baker et al. 1998).

\section{DNA extraction and mtDNA sequencing}

DNA was extracted from epidermis using the Qiagen DNeasy (Qiagen DNeasy, Valencia, CA, USA) kit following the manufacturer's guidelines. DNA yield was quantified using a NanoDrop ND-1000 Spectrophotometer and was between 10 and $50 \mathrm{ng} / \mathbf{1 L}$ for all samples. Twenty-three complete (16 386- to 16 392-bp) and one partial (12 543-bp) mitochondrial genome (mitogenome) sequences had been previously published from our sample set (Morin et al. 2010a), an additional one complete (16 388 bp) and three partial (12 814-14 689 bp) mitogenomes were generated for this study using the highthroughput sequencing methods and primers reported in Morin et al. (2010a). The mtDNA control region (989 bp) was sequenced for the remaining samples using the methods previously reported by Foote et al. (2009).

\section{Microsatellite genotyping}

Samples were genotyped at 17 microsatellite loci (fluorescent dye indicated in parentheses): KW2a (6-FAM; Hoelzel et al. 1998), FCB4 (HEX), FCB5 (NED), FCB11 (6-FAM), FCB12 (HEX), FCB17 (NED; Buchanan et al. 1996), BA417 (6-FAM; Schlötterer et al. 1991), EV1 (HEX), EV37 (NED; Valsecchi \& Amos 1996), Ttru $\mathrm{GT}_{142}$ (HEX), Ttru $\mathrm{AAT}_{44}$ (HEX; Caldwell et al. 2002), Ttr04 (FAM), Ttr11 (FAM; Rosel et al. 2005), D08 (NED), D18 (FAM), D22 (HEX; Shinohara et al. 1997), MK5 (PET; Krü tzen et al. 2001). Each 25 IL PCR contained 1 1L extracted DNA, 10- PCR buffer, $1.0 \mathrm{~mm}$ $\mathrm{MgCl}_{2}, 400 \mathrm{~nm}$ of each primer, $0.1 \mathrm{~mm}$ mixed dNTPs and 0.1 IL AmpliTaq Gold enzyme (Applied Biosystems, Foster City, CA, USA). PCR amplifications were performed using an MJ Thermocycler with a 4-min activation step at $95{ }^{\circ} \mathrm{C}$, followed by 35 cycles of denaturation at $95{ }^{\circ} \mathrm{C}$ for $20 \mathrm{~s}$, annealing for $20 \mathrm{~s}$ at $50{ }^{\circ} \mathrm{C}$ (loci EV1, FCB11, FCB12, KW2a, Ttr11); $54{ }^{\circ} \mathrm{C}$ (BA417, D08, D18, D22, EV37, FCB5, FCB17, Ttr04, Ttru $\mathrm{AAT}_{44}$ ); $60{ }^{\circ} \mathrm{C}$ (FCB4, Ttru $\mathrm{GT}_{142}$ ) or $65^{\circ} \mathrm{C}$ (MK5:), extension at $72{ }^{\circ} \mathrm{C}$ for $20 \mathrm{~s}$, followed by a final extension period of $72{ }^{\circ} \mathrm{C}$ for $7 \mathrm{~min}$. The PCR products were analysed individually on an ABI 3130 DNA sequencer (Applied Biosystems) using a LIZ 500 size standard (Applied Biosystems) as an internal standard to determine allele sizes and scored using GENEMAPPER 4.0 (Applied Biosystems). Ten samples $(>10 \%$ of the data set) were selected at random to be re-amplified and re-genotyped for all 17 loci to assess genotyping errors by estimating the number of differences over the total number of alleles scored. (Bonin et al. 2004; Morin et al. 2010b). Lastly, the genotypes of 10 samples were double-checked (blind to the original scores) for all loci by a second experienced genotyper as recommended by Morin et al. (2010b). The presence of null alleles was tested using MICRO-CHECKER (van Oosterhout et al. 2004).

\section{Clustering analysis}

A Bayesian model-based clustering algorithm performed by structure 2.3 (Pritchard et al. 2000) was used to infer population structure and probabilistically assign individuals to $\mathrm{k}$ clusters minimizing Hardy-Weinberg disequilibrium between loci within groups, without a priori knowledge of population units and limits. A series of five replicate independent runs were conducted for each value of $k$, set between 1 and 6, using the correlated allele frequencies and admixture models (Falush et al. 2003). Each run used $10^{6}$ iterations after a burn-in length of $10^{5}$ iterations. To check for convergence of the Markov chain Monte Carlo (MCMC), we compared the consistency of the results of the five replicates at each value of $k$. The estimated number of clusters, $k$, can be indicated by the run with the highest $\operatorname{Pr}(\mathrm{X} \mid \mathrm{k})$; however, in natural populations $\operatorname{Pr}(\mathrm{X} \mid \mathrm{k})$ frequently continues to increase with increasing $k$ (Pritchard et al. 2000). Therefore, we applied the ad hoc measure of Dk, the second order rate of change of $\ln [\operatorname{Pr}(\mathrm{X} \mid \mathrm{k})]$ with respect to $\mathrm{k}$, which has been suggested to be a more reliable estimator of the number of clusters by Evanno et al. (2005).

\section{Genetic differentiation and genetic diversity among} inferred populations

Pairwise population estimates of genetic differentiation were estimated from allele frequencies using Weir \& 
Cockerham's (1984) $\mathrm{F}_{\mathrm{ST}}$ calculated in FSTAT 2.9.3 (Goudet 1995), and 95\% confidence intervals for FST were estimated from 15000 bootstrap resamplings. For comparison, genetic differentiation between each pair of populations was also estimated using Jost's D, which is independent of heterozygosity (Jost 2008), estimated as the harmonic mean of the pairwise mean values for each loci using SMOGD (Crawford 2010). Genetic diversity measures (expected and observed heterozygosity and $\mathrm{F}_{\mathrm{IS}}$ ) were estimating using GENEPOP (Raymond \& Rousset 1995). Fisher's exact test for deviation from Hardy-Weinberg equilibrium and linkage disequilibrium was performed using GENEPOP.

Genetic distance among the $\mathrm{k}$ structure clusters was computed by applying the neighbour-joining algorithm (Saitou \& Nei 1987) to the matrix of allele-frequency divergence among clusters (net nucleotide distance) as estimated by structure, using the software NEIGHBOR from the PHYLIP package (Felsenstein 2005) as implemented in STRUCTURE.

Pairwise differentiation between each pair of populations based on mtDNA control region haplotype frequency was estimated as $\mathrm{u}_{\mathrm{ST}}$ from an analysis of molecular variance (AMOVA; Excoffier et al. 1992) using GENodive (Meirmans \& Van Tienderen 2004) the significance of which was assessed using 1000 permutations. Probability values were corrected for multiple comparisons using the sequential Bonferroni test (Rice 1989).

\section{Randomization test}

Killer whale pods typically consist of strict matrilines (Bigg et al. 1990; Ugarte 2001; Similä 1997b). Such social organization can bias microsatellite allele frequencies and fix the mtDNA haplotype found in the oldest female, therefore increasing heterogeneity among pods (Amos et al. 1993; Palsbøll et al. 2002). If multiple individuals have been sampled from within pods, heterogeneity among pods can be misinterpreted as population structure (Fullard et al. 2000; Palsbøll et al. 2002). To investigate the effect that sampling matrifocal pods has on heterogeneity within a population, we compared 10 pairs of 10 randomly selected samples from those collected on the Norwegian herring grounds, which included some individuals sampled from the same pod and estimated $\mathrm{F}_{\mathrm{ST}}$ based on microsatellite allele frequencies and $\mathrm{u}_{\mathrm{ST}}$ between mtDNA haplotype frequencies.

\section{Mitogenome phylogenetic analyses}

The sequence coverage and reliability of the two complete and two partial mitogenomes generated specifically for this study were visually assessed by eye using
Geneious 5.0 (Drummond et al. 2010). Specifically, conspicuous indels, SNPs and length differences in homopolymeric regions were checked, and if variation existed among the sequencing reads, the most frequent modifications were assigned as the true state. The influence of potential numts was excluded given the absence of stop codons or frame shifts in the aligned protein encoding genes. The generated mitogenome sequences were then aligned against previously published sequences (Morin et al. 2010a) using the alignment algorithm implemented in the software package GENEIOUs 5.0 (Drummond et al. 2010) and re-inspected by eye using SE-AL 2.0 (Rambaut 2002). Phylogenetic relationships based on the sequence data were estimated using maximum likelihood (ML) methods performed using webserver-based PHYML 3.0 (Guindon \& Gascuel 2003; Guindon et al. 2005), using the HKY + Inv + gamma model selected using jModelTest 1.1 (Posada 2008). The transition/transversion ratio, the proportion of invariable sites, the gamma distribution and the starting tree, estimated using a BIONJ algorithm (Gascuel 1997), a variant of the neighbour-joining algorithm (Saitou \& Nei 1987), were also estimated by pнyмL 3.0. The reliability of the optimized tree was estimated using 100 bootstrap replicates.

\section{Results}

The following results are the first indication of population structure of North Atlantic killer whales using both biparentally inherited nuclear markers (microsatellites) and maternally inherited mtDNA (including complete mitogenome sequences). We were able to successfully amplify and score the alleles of all 17 microsatellite loci for 66 samples and at least 14 of the 17 microsatellite loci for a further 17 samples. Two samples were amplified for $<14$ of the microsatellite and so were not used in further analyses. In addition to the 24 previously sequenced and published mitogenome sequences from our samples, we successfully amplified and sequenced an additional complete (16 388-bp) and three partial (12 814- to 14 689-bp) mitogenomes and the mtDNA control region (989 bp) of the remaining 56 samples (44 of these were previously unpublished, 12 were included in Foote et al. 2009).

Clustering analysis based upon microsatellite variability

Clustering analysis was based upon microsatellite variability. The number of alleles per loci ranged from 3 to 18; the mean was 7.5. No null alleles were detected using Micro-Checker (van Oosterhout et al. 2004). Per allele error rate was estimated at 0.0081 . The value of 
$\operatorname{Pr}(\mathrm{X} \mid \mathrm{k})$ continued incrementally increasing with increasing $\mathrm{k}$ up to $\mathrm{k}=5$ (see Supporting information). The best estimate of $\mathrm{k}$ when applying the ad hoc test of Evanno et al. (2005) was $k=3$. Pritchard et al. (2000) acknowledge the difficulty of accurately estimating $\operatorname{Pr}(\mathrm{X} \mid \mathrm{k})$ in natural populations where isolation by distance or inbreeding may lead to a divergence from a scenario of $\mathrm{k}$ discrete populations with loci at HardyWeinberg equilibrium and typically lead to an overestimate of $\mathrm{k}$. They recommend selecting the smallest value of $k$ where estimates of $\operatorname{Pr}(\mathrm{X} \mid \mathrm{k})$ start to plateau. We have therefore used $k=3$ in further analyses, but assignment results for $k=4$ and $k=5$ are also presented in Fig. 1, and we have removed some individuals assigned to population B from further analysis based on the results for $k=5$.

The first of three inferred populations (population A) included individuals that were confirmed as known herring-feeding killer whales from photo-identification
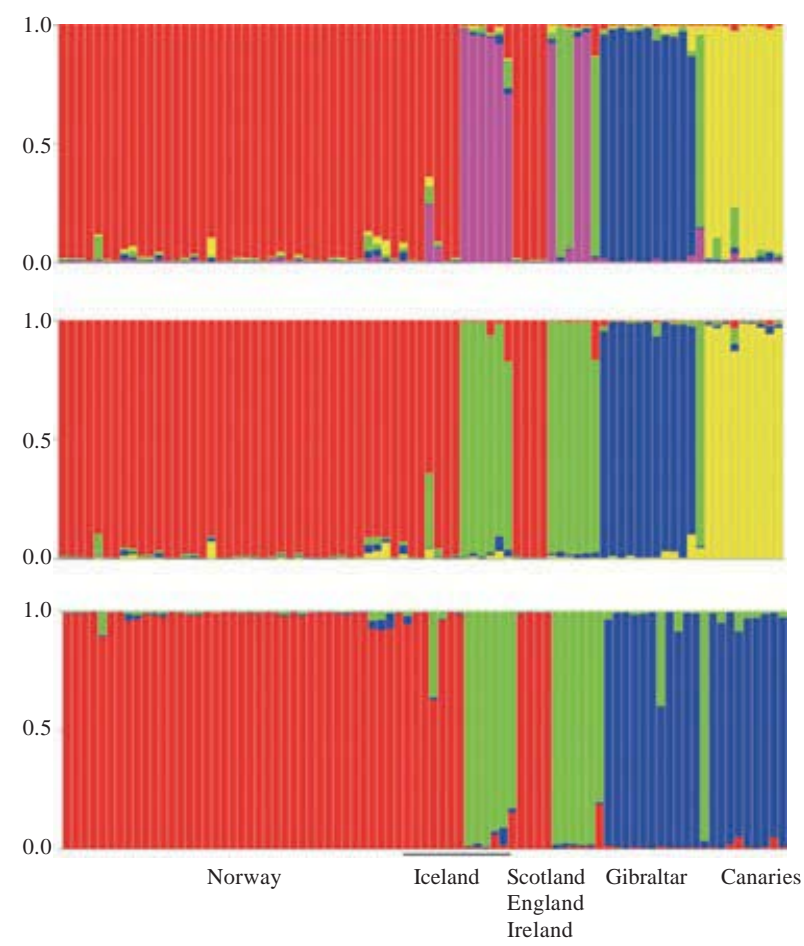

Fig. 1 Population structure for $\mathrm{k}=3$ to $\mathrm{k}=5$ as estimated by STRUCTURE. Each individual is represented by a column and the probability of that individual belonging to each of $\mathrm{k}$ populations is indicated by coloured segments. Each plot is based on the highest probability run (of five) at that value of k. Individuals are arranged on their geographic origin sorted with decreasing latitude from left to right. The individual between Scottish /English /Irish samples and Gibraltar samples stranded on the coast of Newfoundland, Canada, the individual between the Gibraltar and Canary Islands samples was sampled in the Gulf of Mexico. records or were feeding on herring at the time of sampling and/or were sampled within the ranges of the Norwegian, Icelandic and North Sea herring stocks. All individuals assigned to population A were sampled at latitudes $>60^{\circ}$ North (Fig. 2). As a previous analysis using photo-identification data had failed to find any movement of naturally marked individuals between the Norwegian and Icelandic herring grounds (Foote et al. 2010), we performed an ad hoc analysis using sTRUCTURE on the individuals assigned to population A. Runs were repeated with just these samples at $\mathrm{k}=2$, using the no admixture model, which can be more powerful than the admixture model at detecting subtle population structure. Individuals were assigned to either a predefined Iceland or Norway population. We tested whether each individual had an immigrant ancestor in the last two generations at a prior probability of $\mathrm{v}=0.05$. No migrants were detected in the predefined Norwegian population, but two probable $(\mathrm{P}=0.707$ and 0.787 ) Norwegian migrants were detected in the predefined Icelandic population. There was, therefore, some subtle population structuring within population A, consistent with the mark-recapture data (Foote et al. 2010).

All individuals assigned to the second population (population B) were sampled at latitudes from $66^{\circ}$ to $51^{\circ}$ North and from the North Sea to the West coast of Iceland (Figs 1 and 2). These included an individual with mtDNA control region haplotype Atl_1_29, sampled from a pelagic trawler whilst feeding on mackerel discards, and all those from the United Kingdom, Ireland and Iceland sharing this haplotype. Their distribution also overlaps with that of the Northeast Atlantic mackerel stock (Uriarte \& Lucio 2001; Jónsson \& Pálsson 2006). Two individuals previously classified as a distinct ecotype (type 2, see Foote et al. 2009) were also assigned to this population, as were two individuals from the Western North Atlantic. At $\mathrm{k}=5$, this population was split into two clusters, one with all the individuals with control region haplotype Atl_1_29 and another containing the two type 2 samples and the Western North Atlantic samples (Fig. 1). The splitting of population $\mathrm{B}$ at $\mathrm{k}=5$ appeared biologically realistic given the geographic distance between the East and West North Atlantic samples and the ecological and morphological differences between type 1 and type 2 (Foote et al. 2009). We therefore did not include these four samples in further analyses of microsatellite genotypes.

The third population (population C) included the 10 samples from the Strait of Gibraltar, nine of which shared the same control region haplotype (Atl_1_33). These individuals were regularly seen taking tuna both from the long-line fishery, and using an 'enduranceexhaustion’ group hunting technique (Guinet et al. 


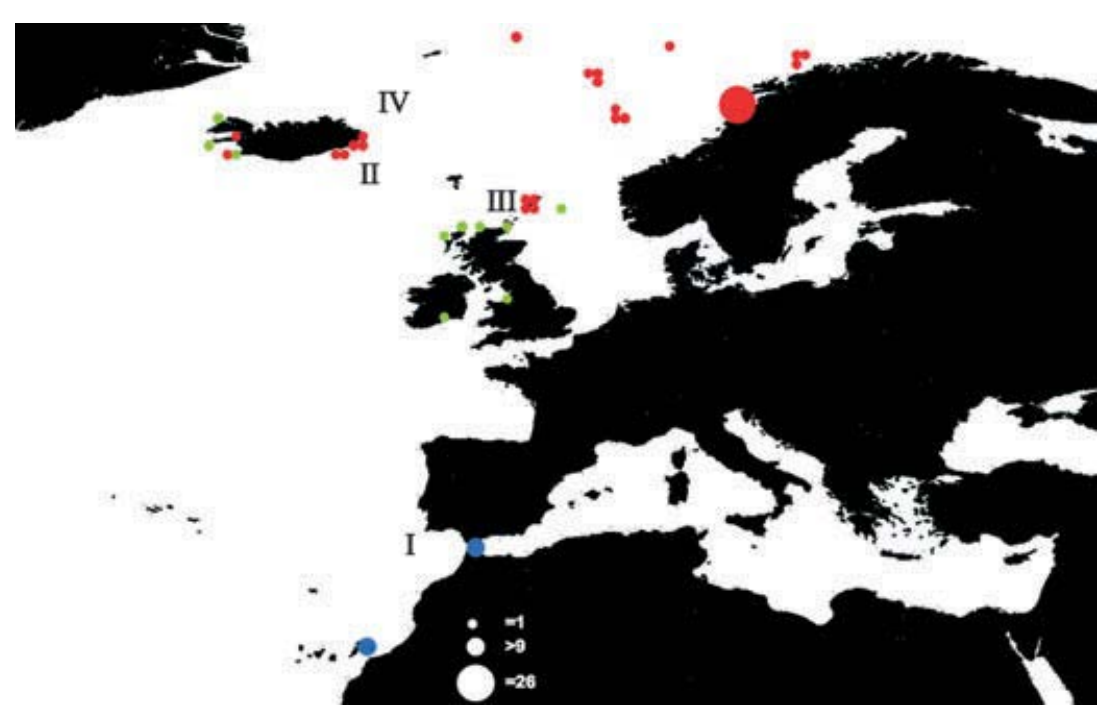

Fig. 2 Map of the Northeast Atlantic showing the approximate geographic sampled locations and sample sizes per location. Population assignment from the highest probability structure run (of five) at $\mathrm{k}=3$ is indicated by colour and corresponds to colours in Fig. 1. Potential contact zones that could result in gene flow and admixture are based on known spatial and temporal overlaps in prey species migrations and are indicated by roman numerals: (I) A component of the Northeast Atlantic mackerel stock spawns off the Iberian peninsula in spring (Uriarte \& Lucio 2001), overlapping spatially and temporally with the occurrence of the eastern stock of Atlantic bluefin tuna (Fromentin \& Powers 2005); (II) The NE Atlantic mackerel stock has recently moved into Icelandic waters overlapping during the summer months with the range of the Icelandic summer-spawning herring (Jónsson \& Pálsson 2006); (III) The North Sea herring stock spawning ground (Mariani et al. 2005; Ruzzante et al. 2006) and the Northeast Atlantic mackerel stock summer migratory path (Uriarte \& Lucio 2001) overlap in waters west of Shetland during the summer; (IV) The Norwegian springspawning and Icelandic summer-spawning stocks of Atlantic herring historically overlapped in range to the North and East of Iceland during the summer months, prior to shifts in migrations in the late 1960s (Røttingen 1990).

2007; Esteban-Pavo 2008; de Stephanis et al. 2008). The remaining individual had mtDNA control region haplotype Atl_1_29. The group containing this individual was only seen in the Strait of Gibraltar in the spring months, when they were only seen predating tuna using the endurance-exhaustion technique (Guinet et al. 2007), but in over 10 years of dedicated summer fieldwork they have not been seen in the Strait during the summer or seen taking tuna from long-line fishing vessels (Esteban-Pavo 2008). All sampled individuals from the two groups sampled off the Canary Islands were also assigned to this population (Figs 1 and 2). One group consisted of individuals with mtDNA control region haplotype Atl_1_28, the other mtDNA control region haplotype Atl_1_29. At $\mathrm{k}=4$, the Canary Island individuals were split from the Gibraltar samples and form their own cluster that persists for higher values of $\mathrm{k}$ (Fig. 1). The additional structuring within population $\mathrm{C}$ at $\mathrm{k} \neq 4$ may be the detection of matrifocal pods rather than additional population structure. Population $\mathrm{C}$, at $\mathrm{k}=3$, contains individuals with three mtDNA control region haplotypes, and the photo-identification data indicate that five different pods were sampled. We investigated the possibility that we were detecting pods, rather than populations, at $\mathrm{k}=4$ using a subset of our data and removing all individuals but one sampled from the same group or on the same day. The best estimate of $\mathrm{k}$ was still 3 , and individuals were assigned to the same populations as for the full data set. Therefore, the Canary Island samples and Gibraltar samples were left as one cluster or population.

Genetic differentiation and genetic diversity among inferred populations

Levels of genetic divergence between the three putative populations were comparable in magnitude and ranking for both distance measures ( $\mathrm{F}_{\mathrm{ST}}$ and $\mathrm{D}$; Table 1). The greatest differentiation was between the two allopatric populations, A and C (Fig. 2). Net nucleotide distances calculated between the three putative populations place population B almost exactly midway between populations A and C. Differentiation between populations based on mtDNA control region haplotypes ( $\mathrm{u}_{\mathrm{ST}}$ ) was higher than for the estimates based on microsatellite allele frequencies (Table 1). There were no shared mitogenome haplotypes (16 mitogenomes were sequenced from samples assigned to population A, two from population B and eight from population C, Fig. 3) and so differentiation estimates based on control region 
Table 1 Pairwise population differentiation based on allelic frequencies of 17 polymorphic microsatellites estimated as $\mathrm{F}_{\mathrm{ST}}$ values (95\% CI)/D (Jost 2008) are given below the diagonal; pairwise population differentiation based on mtDNA control region haplotype frequencies estimated as $\mathrm{u}_{\mathrm{ST}}$ values $(\mathrm{SD})$ is given above the diagonal. All $\mathrm{F}_{\mathrm{ST}}$ values were significant at $(\mathrm{P}<0.05)$; all $\mathrm{u}_{\mathrm{ST}}$ values were significant at $(\mathrm{P}<0.01)$ after Bonferroni correction

\begin{tabular}{llll}
\hline Population & A & B & C \\
\hline A & - & $0.554(0.058)$ & $0.231(0.033)$ \\
B & $0.166(0.104-0.232) / 0.197$ & - & $0.482(0.089)$ \\
C & $0.213(0.156-0.265) / 0.269$ & $0.095(0.089-0.324) / 0.140$ & - \\
\hline
\end{tabular}

haplotypes probably underestimate the true level of differentiation between each populations. There was significant differentiation based on mtDNA control region haplotypes between Icelandic and Norwegian individuals assigned to population $\mathrm{A}\left(\mathrm{u}_{\mathrm{ST}}=0.414, \mathrm{SD}=0.07\right.$, $\mathrm{P}<0.01$ ) and no shared mitogenomes (Fig. 3).

Point estimates of $\mathrm{F}_{\mathrm{ST}}$ and $\mathrm{u}_{\mathrm{ST}}$ were comparable between our total data set and our subset of data for which only one sample per pod was included (see Supporting information). Therefore, pairwise differentiation estimates between populations based on our total data set do not seem to have been greatly increased owing to inclusion of individuals from the same pod. Differentiation based on microsatellite allele frequencies between 10 pairs of 10 randomly selected individuals from the Norwegian component of population A did not differ significantly from zero, (mean $F_{\mathrm{ST}}=0.0074$;
$\mathrm{P}=1.0$ ), nor was there significant differentiation based on mtDNA haplotype frequencies (mean $\mathrm{u}_{\mathrm{ST}}=$ ) 0.111 ; $\mathrm{P}=1.0$ ). This was consistent with the previous findings of Fullard et al. (2000) that merging even small numbers of pods of matrifocal cetaceans can reduce within-population heterogeneity caused by sampling matrilines.

Heterozygosity measures indicate a significant $(\mathrm{P}<$ 0.01 ) deficiency of heterozygotes at five loci for population A, two for population B and four for population C (see Supporting information). Population genetic factors, such as undetected null alleles (no null alleles were detected using MICRO-CHECKER, van Oosterhout et al. 2004), further population structuring (Wahlund effect) or other deviations from the model equilibrium conditions may be the cause. There were no loci showing significant departure from Hardy-Weinberg

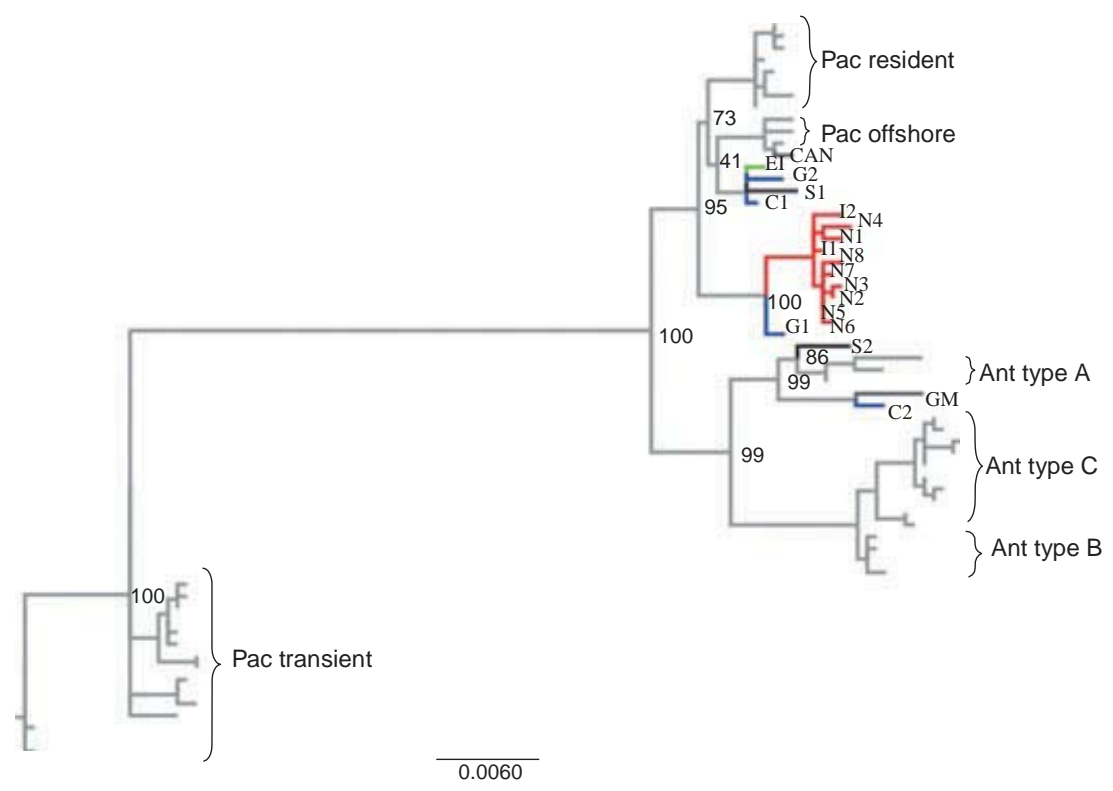

Fig. 3 Phylogenetic relationship between mitogenome haplotypes, displayed as a maximum likelihood phylogenetic tree. Bootstrap values are indicated for nodes of interest. Coloured branches indicate population assignment and correspond to the colour key used in Figs 1 and 2 e.g. population $\mathrm{A}=$ red; population $\mathrm{B}=$ green; population $\mathrm{C}=$ blue. Black nodes indicate specimens previously classified as the type 2 ecotype (Foote et al. 2009), dark grey nodes indicate Western North Atlantic samples. Haplotype codes match the last two digits of those used in Morin et al. (2010a). C1, C2, S2 and G2 are new haplotypes generated for this study. Pacific (Pac) and Antarctic (Ant) ecotypes from Morin et al. (2010a) are included for reference. 
expectations in population $\mathrm{C}$ when only the subset of data excluding multiple individuals from the same pod were included.

\section{Mitogenome phylogenetic analysis}

The mitogenome tree produced by PHYML using the HKY + I + G model had a log-likelihood of )24 239.70 and had the following parameters: gamma shape parameter $=1.307$; a proportion of invariable sites = 0.89 ; equilibrium base frequencies of $0.33,0.27,0.13$ and 0.27 for $\mathrm{A}, \mathrm{C}, \mathrm{G}$ and $\mathrm{T}$ nucleotides, respectively.

This mitogenome phylogeny extends the North Atlantic analyses of Morin et al. (2010a), through the inclusion of additional key samples. Previously, two disparate and sympatric ecotypes of killer whale were characterized in the North Atlantic (Foote et al. 2009). These two types (type 1 and type 2) were divergent in total body length, tooth count, pigmentation, niche width indicated by stable isotope ratios and tooth wear (Foote et al. 2009). Field observations from Bear Island, Svalbard, Northern Iceland and West Scotland, stomach contents from a Fareoese specimen and stable isotope ratios suggest minke whales and pelagic dolphins may be the main prey species of this type 2 (Foote et al. 2009; Foote unpublished data). A new sequence, generated for this study, of a type 2 mitogenome (ENA_Scotland2) was grouped into a clade containing an individual from one of the Canary Islands, and with an individual from the Gulf of Mexico, that was sampled while predating a sperm whale and the Antarctic type A ecotype (Fig. 3), which are also thought to specialize in predating minke whales (Pitman \& Ensor 2003). The mitogenome (ENA_Scotland1) of another previously published putative type 2 specimen for which we had only two samples and less ecological and morphological data (Foote et al. 2009) was placed in a different clade (Morin et al. 2010a; Fig. 3) suggesting either paraphyly of this ecotype, or that haplotype ENA_Scotland1 (control region: ENA_2_27) belongs to an additional, as yet unknown, ecotype.

All the mitogenomes of killer whales sampled on the Icelandic and Norwegian herring grounds and assigned to population A formed a monophyletic clade (Fig. 3). There was incomplete lineage sorting of Icelandic and Norwegian mitogenome haplotypes. Two mitogenomes successfully sequenced from individuals assigned to population B, one from Iceland and one from England, were identical and fell into a clade most closely clustered to the Pacific Offshore ecotype. As noted previously (Morin et al. 2010a,b), a sample from Newfoundland, Canada, was included in the Offshore clade. No other North Atlantic mitogenomes were included in this clade. Four mitogenome haplotypes were found for individuals assigned to Population C: two from individuals sampled in the Strait of Gibraltar, and two from individuals sampled off the Canary Islands. These four mitogenomes fell into three highly divergent clades, and pairwise \% identity was only $84.9 \%$ (compared with $99.97 \%$ for sequences from population $\mathrm{A}$, and $100 \%$ for sequences for population B). Phylogenetic divergences therefore only partially overlapped with phylogeographic differentiation.

\section{Discussion}

This study provides the first molecular characterization of population structure of killer whales in the North Atlantic using both biparentally inherited nuclear DNA markers and maternally inherited mtDNA markers including complete mitochondrial genomes. The results suggest that there are at least three differentiated populations represented by our samples: a population that was associated with North Atlantic herring, including the North Sea, Norwegian spring-spawning and Icelandic summer-spawning stocks; a population associated with the Northeast mackerel stock; and a population that was at least partially associated with the eastern stock of North Atlantic bluefin tuna but included groups of unknown ecology. Population structure therefore appears to be influenced by prey movement, and the greatest differentiation of nuclear markers was between the two allopatric populations.

A difficulty in determining population structure in the killer whale and other species with strict matrilineal social structure such as long-finned pilot whales (Globicephala melas, Fullard et al. 2000) or belugas (Delphinapterus leucas, Palsbøll et al. 2002) is obtaining sufficient sample sizes from each putative population without sampling multiple individuals from within a matrifocal pod. There is then a risk of detecting social structure rather than populations structure (Fullard et al. 2000; Palsbøll et al. 2002) and that including multiple individuals from within a pod with shared maternal ancestry can inflate $\mathrm{F}_{\mathrm{ST}}$ values between populations through allelic enrichment (Amos et al. 1993). This does not seem to be a source of bias in the current study because the structure analysis returned the same number of putative populations when only one individual from each sampled pod was included, and the levels of genetic divergence between them were equivalent.

There are other additional factors influencing the study of population structure of Northeast Atlantic killer whales. They have been heavily exploited over a short time period, e.g. between 1971 and 1981345 individuals were taken from the Norwegian spring-spawning herring wintering grounds at Lofoten (Øien 1988). 
Mark-recapture estimates suggest that approximately 600 individuals were present in the Lofoten area at the time of biopsy sampling for samples used in this study (Kuningas et al. 2007). Such a dramatic reduction in population size could influence population growth and have an effect on allele frequencies and heterozygozity. Second, sexual-size dimorphism in killer whales suggests that mating may not be random. Lastly, the prey species of these populations are known to undergo large-scale shifts in migration (Røttingen 1990; Jakobsson \& Østvedt 1999), which could lead to changes in gene flow among the killer whale groups that follow them and additional subtle social structure within populations (Wahlund effect), as detected here for population A. All these factors could lead to departure from Hardy-Weinberg expectations and migration-driftmutation equilibrium (none of the analyses performed here assume migration-drift-mutation equilibrium).

The level of differentiation based on microsatellite allele frequencies was highest between populations A and $\mathrm{C}$ and was comparable to between ecotype comparisons from the Pacific (Hoelzel et al. 2007; Morin et al. 2010a), but lower than between ecotype comparisons from the Antarctic (Morin et al. 2010a). There were no putative contact points based on prey movements between populations $\mathrm{A}$ and $\mathrm{C}$, and the two populations are thought to be allopatric. There were potential contact points between populations $\mathrm{A}$ and $\mathrm{B}$, and populations $\mathrm{B}$ and $\mathrm{C}$, based on the movement of the prey species that each population is thought to exploit, which could promote gene flow among them. This was reflected in the lower $\mathrm{F}_{\mathrm{ST}}$ values in the pairwise comparison between these populations. The results were also consistent, to some extent, with direct measures of dispersal from mark-recapture analysis of naturally marked photo-identified individuals (Similä et al. 1996; Esteban-Pavo 2008; de Stephanis et al. 2008; Foote et al. 2010), which indicated high site fidelity and philopatry to particular prey resources.

One aspect that differs from the mark-recapture photo-identification data was the clustering of the Icelandic and Norwegian herring-feeding communities. Mark-recapture data suggested that some pods followed the Icelandic summer-spawning herring stock and others followed the Norwegian spring-spawning stock but that there was no movement between the two (Simon et al. 2007; Foote et al. 2010). The significant differentiation based on mtDNA haplotypes between the Icelandic and Norwegian individuals assigned to this population would be consistent with maternal lineages following either herring stock, but not dispersing between stocks. Prior to the mid-1960s, the ranges of the Norwegian spring-spawning and Icelandic summerspawning herring stocks spatially and temporally over- lapped during the summer to the North and East of Iceland (Røttingen 1990; Jakobsson \& Østvedt 1999), potentially allowing for male-mediated gene flow between the communities of killer whale following each stock. Icelandic, Norwegian and Shetland herring-eating killer whale communities use the same complex coordinated feeding strategy and share some vocalizations that are thought to be socially learnt, further suggesting they are ecologically equivalent and that there has been historic contact between them (Strager 1995; Simon et al. 2007; Samarra et al. 2010).

Paraphyly of Icelandic and Norwegian mitogenomes within population A could be attributed to either incomplete lineage sorting owing to the recent divergence of the two communities, or introgressive gene flow (see Piertney et al. 2001). Both seem plausible; it is thought to take approximately $4 \mathrm{~N}_{\mathrm{e}}$ generations following isolation to attain reciprocal monophyly, where $\mathrm{N}_{\mathrm{e}}$ is the effective population size (Avise et al. 1984). Given the large estimated abundance of the Icelandic and Norwegian herring-eating killer whale subpopulations (Gunnlaugsson \& Sigurjónsson 1990; Kuningas et al. 2007), this would take several thousand years for this population. We also detected Norwegian migrants in the Icelandic samples assigned to population A, suggesting some level of recent or ongoing introgressive gene flow.

The two Northern populations (A and B) consisted of a single mtDNA control region and mitogenome haplotype, or a monophyletic clade of mtDNA haplotypes differing by just 1-2 bp, suggesting matrifocal expansion following as few as a single founding event. In contrast, the most southerly population (C) consisted of three mtDNA control region (four mitogenome) haplotypes from three highly divergent clades. There are parallels here with findings from the Pacific; the fixation of mtDNA haplotype within populations at high latitudes (Hoelzel et al. 2007), where killer whale density is greatest (Forney \& Wade 2007). At lower latitudes in eastern tropical Pacific, where killer whale density is relatively low, groups containing multiple and disparate mtDNA haplotypes have been sampled (Waples \& Clapham 2004). This could suggest that female dispersal occurs at lower latitudes but is relatively rare at higher latitudes. However, individuals sampled at lower latitudes from within the same pod shared the same mtDNA haplotype, suggesting philopatry to the matrifocal group just as at higher latitudes. The observed pattern may also result from male-mediated gene flow during temporary interactions, which at lower densities may occur as frequently between more distantly related and even ecologically disparate pods, as they do between maternally related pods. Differences in stable isotope ratios (Garcia Tiscar 2009) and parasite load, 
e.g. cookie cutter sharks and Xenobalanus barnacles (see Mackenzie 2002), among the pods assigned to population $\mathrm{C}$ suggest that they do not belong to a cohesive population that follows the same resource all year round. Gene flow may instead occur during seasonal spatiotemporal overlap. Such a mating system has been suggested for Pacific killer whales (Hoelzel et al. 2007; Pilot et al. 2010) and other species showing low dispersal from the natal matriline (e.g. long-finned pilot whales Amos et al. 1993; beluga Brown-Gladden et al. 1999; African elephant Loxodonta africana Nyakaana \& Arctander 1999).

Our results further indicate the importance of resource specialization on population structuring in species with strict matrifocal philopatry, even when this resource is relatively similar (e.g. different pelagic fish stocks) and does not lead to adaptive divergence. We argue that matrifocal expansion following founding events and male-mediated gene flow between populations, which is dependent upon spatial and temporal overlap, best explains the pattern observed here. These findings reflect earlier studies in the Pacific (Hoelzel et al. 2007; Pilot et al. 2010), suggesting this pattern may be consistent between ocean basins in the killer whale and also reflects findings in other species with a matrilineal social structure (e.g. Amos et al. 1993; Brown-Gladden et al. 1999; Nyakaana \& Arctander 1999).

\section{Acknowledgements}

We thank members of the Piertney laboratory group, University of Aberdeen, and in particular Jane DeGabriel, Freda Marshall and Gill Murray-Dickson and laboratory mates at the Centre for GeoGenetics, University of Copenhagen, and in particular, Rasmus Heller and Sylvia Mathiasen, for assistance in the laboratory and with data analysis. Valentina Islas, Kim Parsons, Phil Morin, Rick LeDuc, Per Palsbøll, Chris Pampoulie, Ruth Esteban, John Durban, Bob Pitman, the editor William Amos and three anonymous reviewers provided useful discussions and comments. We additionally thank Peter Kvadsheim of the FFI, Patrick Miller and Filipa Samarra of SMRU, Ari Shapiro of WHOI and George William Anderson and the crew of the FV Adenia who provided support and platforms for sampling. Harriet Bolt, Odd Petter Hovde, Sanna Kuningas, Sinead Murphy, Filipa Samarra and Hans Wolkers provided additional logistical support during the collection of samples used in this study. All samples were taken under the relevant permits, Vincent Janik generously incorporated this project into his research permit and John Durban and Simon Ingram provided valuable training in biopsy sampling. Funding was provided by Carnegie Trust for the Universities of Scotland, the Marie Curie Actions 'GENETIME' grant fund, the Danish National Science Foundation 'Skou' award program, the Marine Scotland (Scottish Government), Scottish Natural Heritage and an Aberdeen University 6th Century Scholarship to ADF.

\section{References}

Amos W, Hoelzel AR (1991) Long-term preservation of whale skin for DNA analysis. Reports of the International Whaling Commission, Special Issue 13, 99-103.

Amos W, Schlötterer C, Tautz D (1993) Social structure of pilot whales revealed by analytical DNA typing. Science, 260, 670672.

Avise JC, Nigel JE, Arnold J (1984) Demographic influences on mitochondrial DNA lineage survivorship in animal populations. Journal of Molecular Evolution, 20, 99-105.

Baird RW, McSweeney DJ, Bane C et al. (2005) Killer whales in Hawaiian waters: information on population identity and feeding habits. Pacific Science, 60, 523-530.

Baker CS, Medrano-Gonzalez L, Calambokidis J et al. (1998) Population structure of nuclear and mitochondrial DNA variation among humpback whales in the North Pacific. Molecular Ecology, 7, 695-707.

Bigg MA, Olesiuk PF, Ellis GM, Ford JKB, Balcomb III KC (1990) Social organization and genealogy of resident killer whales (Orcinus orca) in the coastal waters of British Columbia and Washington State. Reports of the International Whaling Commission special issue, 12, 383-405.

Bonin A, Bellemain E, Bronken Eidsen P, Pompanon F, Brochmann C, Taberlet P (2004) How to track and assess genotyping errors in population genetics studies. Molecular Ecology, 13, 3261-3273.

Brown-Gladden JG, Ferguson MM, Friezen MK, Clayton JW (1999) Population structure of North American beluga whales (Delphinapterus leucas) based on nuclear DNA microsatellite variation and contrasted with the population structure revealed by mitochondrial DNA variation. Molecular Ecology, 8, 347-363.

Buchanan FC, Freiesen MK, Littlejohn RP, Clayton JW (1996) Microsatellites from the beluga whale Delphinapterus leucas. Molecular Ecology, 5, 571-575.

Caldwell M, Gaines MS, Hughes CR (2002) Eight polymorphic microsatellite loci for bottlenose dolphin and other cetacean species. Molecular Ecology Notes, 2, 393-395.

Carlsson J, McDowell JR, Diaz-Jaimes P et al. (2004) Microsatellite and mitochondrial DNA analyses of Atlantic bluefin tuna (Thunnus thynnus thynnus) population structure in the Mediterranean Sea. Molecular Ecology, 13, 3345-3356.

Crawford NG (2010) SMOGD: software for the measurement of genetic diversity. Molecular Ecology Resources, 10, 566-567.

Drummond AJ, Ashton B, Cheung M et al. (2010) GeneIous 5.0. Available at: http://www.geneious.com/.

Esteban-Pavo R (2008) Abundancia, estructura social y parámetros de historia natural de las orcas (Orcinus orca) del Estrecho de Gibraltar. MSc thesis, University of Cadiz. Available at: http://www.circe.biz.

Evanno G, Regnaut S, Goudet J (2005) Detecting the number of clusters of individuals using the software STRUCTURE: a simulation study. Molecular Ecology, 14, 2611-2620.

Excoffier L, Smouse PE, Quattro JM (1992) Analysis of molecular variance inferred from metric distances among DNA haplotypes-application to human mitochondrial-DNA restriction data. Genetics, 131, 479-491.

Falush D, Stephens M, Pritchard JK (2003) Inference of population structure: extensions to linked loci and correlated allele frequencies. Genetics, 164, 1567-1587. 
Felsenstein J (2005) PHYLIP (Phylogeny Inference Package) version 3.6. Available at: http://evolution.genetics.washington.edu/ phylip.html.

FitzSimmons NH, Goldizen AR, Norman JA et al. (1997) Philopatry of male marine turtles inferred from mitochondrial markers. Proceedings of the National Academy of Sciences, USA, 94, 8912-8917.

Fontaine MC, Baird SJE, Piry S et al. (2007) Rise of oceanographic barriers in continuous populations of a cetacean: the genetic structure of harbour porpoises in Old World waters. BMC Biology, 5, 30.

Fontaine MC, Tolley KA, Michaux JR et al. (2010) Genetic and historic evidence for climate-driven population fragmentation in a top cetacean predator: the harbour porpoises in European water. Proceedings of the Royal Society B, 277, 2829-2837.

Foote AD, Newton J, Piertney SB, Willerslev E, Gilbert MTP (2009) Ecological, morphological and genetic divergence of sympatric North Atlantic killer whale populations. Molecular Ecology, 18, 5207-5217.

Foote AD, Similä T, Víkingsson GA, Stevick PT (2010) Movement, site fidelity and connectivity in a top marine predator, the killer whale. Evolutionary Ecology, 24, 803-814.

Forney KA, Wade P (2007) Worldwide distribution and abundance of killer whales. In: Whales, whaling and ecosystems (ed. Estes J), pp. 145-162, University of California Press.

Fromentin J-M, Powers JE (2005) Atlantic bluefish tuna: population dynamics, ecology, fisheries and management. Fish \& Fisheries, 6, 281-306.

Fullard KJ, Early G, Heide-Jørgensen MP, Bloch D, RosingAsvid A, Amos W (2000) Population structure of long-finned pilot whales in the North Atlantic: a correlation with sea surface temperature? Molecular Ecology, 9, 949-958.

Garcia Tiscar S (2009) Interacciones entre delfines mulares y orcas con pesqeuerías en el Mar deAlborán y Estrecho de Gibraltar. PhD thesis, Universidad Autó noma de Madrid.

Gascuel O (1997) BIONJ: an improved version of the NJ algorithm based on a simple model of sequence data. Molecular Biology and Evolution, 14, 685-695.

Goudet J (1995) FSTAT version 1.2: a computer program to calculate F-statistics. Journal of Heredity, 86, 485-486.

Guindon S, Gascuel O (2003) A simple, fast, and accurate algorithm to estimate large phylogenies. Systematic Biology, 52, 696-704.

Guindon S, Lethiec F, Duroux P, Gascuel O (2005) PHYML onlinea web server for fast maximum likelihood-based phylogenetic inference. Nucleic Acids Research, 33, W557-W559.

Guinet C, Domencini P, de Stephanis R et al. (2007) Killer whale predation on bluefin tuna: exploring the hypothesis of the endurance-exhaustion technique. Marine Ecology Progress Series, 347, 111-119.

Gunnlaugsson T, Sigurjónsson J (1990) NASS-87: estimation of whale abundance based on observations made onboard Icelandic and Faroese survey vessels ship-board. Reports of the International Whaling Commission, 40, 571-580.

Hoelzel AR (1998) Genetic structure of cetacean populations in sympatry, parapatry and mixed assemblages; implications for conservation policy. Journal of Heredity, 89, 451-458.

Hoelzel AR, Dahlheim M, Stern SJ (1998) Low genetic variation among killer whales (Orcinus orca) in the Eastern North Pacific and genetic differentiation between foraging specialists. Journal of Heredity, 89, 121-128.
Hoelzel AR, Hey J, Dahlheim ME et al. (2007) Evolution of population structure in a highly social top predator, the killer whale. Molecular Biology \& Evolution, 24, 1407-1415.

Jakobsson J, Østvedt OJ (1999) A review of joint investigations on the distribution of herring in the Norwegian and Icelandic Seas 1950-1970. Rit Fiskideildar, 16, 209-238.

Johnson M, Tyack P, Nowacek D, Shorter A (2000) A digital acoustic recording tag for measuring the response of marine mammals to sound. Journal of the Acoustical Society of America, 108, 2582-2583.

Jónsson G, Pálsson J (2006) Íslenskir fiskar (Icelandic Fishes). Reykjavík, Iceland, $336 \mathrm{pp}$.

Jordan MA, Snell HL (2008) Historical fragmentation of islands and genetic drift in populations of Galápagos lava lizards (Microlophus albemarlensis complex). Molecular Ecology, 17, $1224-1237$.

Jost L (2008) $\mathrm{G}_{\mathrm{ST}}$ and its relatives do not measure differentiation. Molecular Ecology, 17, 4015-4026.

Krü tzen M, Valsecchi E, Connor RC, Sherwin WB (2001) Characterization of microsatellite loci in Tursiops aduncus. Molecular Ecology Notes, 1, 170-172.

Kuningas S, Similä T, Hammond PS (2007) Population Dynamics of Killer Whales (Orcinus orca) off Northern Norway. Report to Scientific Committee of the International Whaling Commission Anchorage, SC/59/SM13.

Luque PL, Davis CG, Reid DG, Wang J, Pierce GJ (2006) Opportunistic sightings of killer whales from Scottish pelagic trawlers fishing for mackerel and herring off North Scotland (UK) between 2000 and 2006. Aquatic Living Resources, 19, 403-410.

Mackenzie K (2002) Parasites as biological tags in population studies of marine organisms: an update. Parasitology, 124, S153-S163.

Mariani S, Hutchinson WF, Hatfield EMC et al. (2005) North Sea herring population structure revealed by microsatellite analysis. Marine Ecology Progress Series, 303, 245-257.

Mayr E (1942) Systematics and the Origin of Species. Columbia University Press, New York.

Meirmans PG, Van Tienderen PH (2004) Genotype and GENODIVE: two programs for the analysis of genetic diversity of asexual organisms. Molecular Ecology Notes, 4, 792-794.

Morin PA, Archer FI, Foote AD et al. (2010a) Complete mitochondrial genome phylogeographic analysis of killer whales (Orcinus orca) indicates multiple species. Genome Research, 20, 908-916.

Morin PA, Martien KK, Archer FI et al. (2010b) Applied conservation genetics and the need for quality control and reporting of genetic data used in fisheries and wildlife management. Journal of Heredity, 101, 1-10.

Natoli A, Birkun A, Aguilar A, Lopez A, Hoelzel AR (2005) Habitat structure and dispersal of male and female bottlenose dolphins (Tursiops truncatus). Proceedings of the Royal Society B, 272, 1217-1226.

Nyakaana S, Arctander P (1999) Population genetic structure of the African elephant in Uganda based on variation at the mitochondrial and nuclear loci: evidence for male-biased gene flow. Molecular Ecology, 8, 1105-1115.

Øien N (1988) The distribution of killer whales (Orcinus orca) in the North Atlantic based on Norwegian catches, 19381981, and incidental sightings, 1967-1987. Rit Fiskideildar, 11, 65-78. 
van Oosterhout C, Hutchinson WF, Wills DPM, Shipley P (2004) MICRO-CHECKER: software for identifying and correcting genotyping errors in microsatellite data. Molecular Ecology Notes, 4, 535-538.

Palsbøll PJ, Larsen F, Hansen ES (1991) Sampling of skin biopsies from free-ranging large cetaceans in West Greenland: development of new biopsy tips and bolt designs. Reports of the International Whaling Commission, Special Issue 13, 71-79.

Palsbøll PJ, Heide-Jørgensen MP, Dietz R (1997) Population structure and seasonal movements of narwhals, Monodon monoceros, determined from mtDNA analysis. Heredity, 78, 284-292.

Palsbøll PJ, Heide-Jørgensen MP, Bérubé M (2002) Analysis of mitochondrial control region nucleotide sequences from Baffin Bay belugas (Delphinapterus leucas): detecting pods or sub-populations? In:Belugas in the North Atlantic and Russian Arctic (eds Heide-Jørgensen MP, Wiig Ø). pp. 3950, North Atlantic Marine Mammal Commission, Tromsø, Norway.

Palsbøll PJ, Bérubé M, Aguilar A, Notarbartolo-Di-Sciara G, Nielsen R (2004) Discerning between recurrent gene flow and recent divergence under a finite-site mutation model applied to North Atlantic and Mediterranean Sea fin whale (Balaenoptera physalus) populations. Evolution, 58, 670-675.

Palumbi SR (1994) Genetic divergence, reproductive isolation, and marine speciation. Annual Review of Ecology and Systematics, 25, 547-572.

Pardini AT, Jones CS, Noble LR et al. (2001) Sex-biased dispersal of great white sharks. Nature, 412, 139-140.

Pastene LA, Mutsuo G, Kanda N et al. (2007) Radiation and speciation of pelagic organisms during periods of global warming: the case of the common minke whale, Balaenoptera acutorostrata. Molecular Ecology, 16, 1481-1495.

Piertney SB, Summers R, Marquiss M (2001) Microsatellite and mitochondrial DNA homogeneity among phenotypically diverse crossbill taxa in the UK. Proceedings of the Royal Society of London B, 268, 1511-1517.

Piertney SB, Stewart WA, Lambin X, Telfer S, Aars J, Dallas JF (2005) Phylogeographic structure and postglacial evolutionary history of water voles (Arvicola terrestris) in the United Kingdom. Molecular Ecology, 14, 1435-1444.

Pilot M, Dahlheim ME, Hoelzel AR (2010) Social cohesion among kin, gene flow without dispersal and the evolution of population structure in the killer whale (Orcinus orca). Journal of Evolutionary Biology, 23, 20-31.

Pitman RL, Ensor P (2003) Three forms of killer whales (Orcinus orca) in Antarctic waters. Journal of Cetacean Research and Management, 5, 131-139.

Pitman RL, Fearnbach H, LeDuc R, Gilpatrick JW, Ford JKB, Ballance LT (2007) Killer whales preying on a blue whale calf on the Costa Rica Dome: genetics, morphometrics, vocalisations and composition of the group. Journal of Cetacean Research and Management, 9, 151-157.

Posada D (2008) jModelTest: phylogenetic model averaging. Molecular Biology \& Evolution, 25, 1253-1256.

Pritchard JK, Stephens M, Donnelly P (2000) Inference of population structure using multilocus genotype data. Genetics, 155, 945-959.

Rambaut A (2002) Sequence-alignment editor, version 2.0. Available at: http://tree.bio.ed.ac.uk/software/seal/.
Raymond M, Rousset F (1995) GENEPOP (version 1.2): population genetics software for exact tests and ecumenicism. Journal of Heredity, 86, 248-249.

Rice WR (1989) Analyzing tables of statistical tests. Evolution, 43, 223-225.

Rosel PE, Forgetta V, Dewar K (2005) Isolation and characterization of twelve polymorphic microsatellite markers in bottlenose dolphins (Tursiops truncatus). Molecular Ecology Notes, 5, 830-833.

Røttingen I (1990) A review of the variability in the distribution and abundance of Norwegian spring spawning herring and Barents Sea capelin. Polar Research, 8, 33-42.

Ruzzante DE, Mariani S, Bekkevold D et al. (2006) Biocomplexity in a highly migratory pelagic marine fish, Atlantic herring. Proceedings of the Royal Society of London B, 273, 1459-1464.

Saitou N, Nei M (1987) The neighbor-joining method: a new method for reconstructing phylogenetic trees. Molecular Biology \& Evolution, 4, 406-425.

Sakai Y, Hayashi R, Murata K, Yamada TK, Asakawa M (2009) Records of barnacle, Xenobalanus globicipitis Steenstrup, 1851 and whale lice, Cyamus sp. From a wild killer whale captured in the western North Pacific, off Kii Peninsula, Japan. Japanese Journal of Zoo and Wildlife Medicine, 14, 81-84.

Samarra FIP, Deecke VB, Vinding K, Rasmussen MH, Swift R, Miller PJO (2010) Killer whales (Orcinus orca) produce ultrasonic whistles. Journal of the Acoustical Society of America, 128, EL205-EL210.

Schlötterer C, Amos B, Tautz D (1991) Conservation of polymorphic simple sequence loci in cetacean species. Nature, 354, 63-65.

Shinohara M, Domingo-Roura X, Takenaka O (1997) Microsatellites in the bottlenose dolphin Tursiops truncatus. Molecular Ecology, 6, 695-696.

Sigurjónsson J, Leatherwood S (1988) The Icelandic live-capture fishery for killer whales, 1976-1988. Rit Fiskideildar, 11, 307316.

Sigurjónsson J, Lyrholm T, Leatherwood S, Jónsson E, Víkingsson GA (1988) Photoidentification of killer whales, Orcinus orca, off Iceland, 1981 through 1986. Rit Fiskideildar, 11, 99-114.

Similä T (1997a) Sonar observations of killer whales (Orcinus orca) feeding on herring schools. Aquatic Mammals, 23, 119126.

Similä T (1997b) Behavioural ecology of killer whales in Northern Norway. PhD thesis. NFH, University of Tromsø.

Similä T, Ugarte F (1993) Surface and under-water observations of cooperatively feeding killer whales in northern Norway. Canadian Journal of Zoology, 71, 1494-1499.

Similä T, Holst JC, Christensen I (1996) Occurrence and diet of killer whales in northern Norway: seasonal patterns relative to the distribution and abundance of Norwegian springspawning herring. Canadian Journal of Fisheries and Aquatic Sciences, 53, 769-779.

Simon M, McGregor PK, Ugarte F (2007) The relationship between the acoustic behaviour and surface activity of killer whales (Orcinus orca) that feed on herring (Clupea harengus). Acta Ethologia, 10, 47-53.

de Stephanis R, Cornulier T, Verborgh P et al. (2008) Summer spatial distribution of cetaceans in the Strait of Gibraltar in 
relation to the oceanographic context. Marine Ecology Progress Series, 353, 275-288.

Strager H (1995) Pod-specific call repertoires and compound calls of killer whales, Orcinus orca, in the waters of northern Norway. Canadian Journal of Zoology, 73, 1037-1047.

Tucker VA (1975) The energetic cost of moving about. American Scientist, 63, 413-419.

Ugarte F (2001) Behaviour and social organization of killer whales in northern Norway. MSc thesis, University of Tromsø.

Uriarte A, Lucio P (2001) Migration of adult mackerel along the Atlantic European shelf edge from a tagging experiment in the south of the Bay of Biscay in 1994. Fisheries Research, 50, 129-139.

Valsecchi E, Amos W (1996) Microsatellite markers for the study of cetacean populations. Molecular Ecology, 5, 151-156.

Waples RS, Clapham PJ (2004) Report of the working group on killer whales as a case study. In: Report of the Workshop on Shortcomings of Cetacean Taxonomy, 28-29 April 2004, La Jolla, CA.

Weir BS, Cockerham CC (1984) Estimating F-statistics for the analysis of population structure. Evolution, 38, 1358-1370.

Williams TM (1999) The evolution of cost efficient swimming in marine mammals: limits to energetic optimization. Philosophical Transactions of the Royal Society B, 354, 193-201.

A.D.F. studies evolutionary processes in marine mammals, principally killer whales, with a particular focus on the interaction between ecology, phenotype and genotype. E.W. works in the fields of ancient DNA, DNA degradation, and evolutionary biology, with a particular interest in ancient sedimentary and ice core genetics. M.T.P.G. is a molecular biologist with broad scale evolutionary, anthropological and archaeological interests that he studies using both modern and ancient DNA. S.B.P. is a molecular ecologist with a focus on understanding the causes and consequences of variation in levels of genetic diversity among natural populations.

\section{Supporting information}

Additional supporting information may be found in the online version of this article:

Fig. S1 Mean $( \pm)$ probabilities of the data $[\ln \operatorname{Pr}(X \mid k)]$ over 5 STRUCTURE replicated runs plotted as a function of the putative number of clusters $(\mathrm{k})$

Table S1 Genetic variation across the 17 microsatellite loci for the populations inferred by STRUCTURE

Table S2 Pairwise population differentiation $\left(\mathrm{F}_{\mathrm{ST}}\right)$ based on allelic frequencies of 17 polymorphic microsatellites of all samples assigned to each population followed by the same estimate for a subset of the data which excludes individuals from the same pod are given below the diagonal

Please note: Wiley-Blackwell are not responsible for the content or functionality of any supporting information supplied by the authors. Any queries (other than missing material) should be directed to the corresponding author for the article. 